\title{
Fatal chytridiomycosis and infection loss observed in captive toads infected in the wild
}

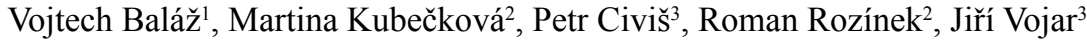 \\ ${ }^{1}$ University of Veterinary and Pharmaceutical Sciences Brno, Faculty of Veterinary Hygiene and Ecology, \\ Department of Biology and Wildlife Diseases, Brno, Czech Republic \\ ${ }^{2}$ NaturaServis Ltd., Hradec Králové, Czech Republic \\ ${ }^{3}$ Czech University of Life Sciences Prague, Faculty of Environmental Sciences, Department of Ecology, \\ Prague, Czech Republic
}

Received March 5, 2013

Accepted September 26, 2013

\begin{abstract}
:
A parasitic fungus, Batrachochytrium dendrobatidis is now recognised as an important factor in the amphibian biodiversity crisis. Toad species of the genus Bufo are among those susceptible to infection by the pathogen in Europe. The aim of this study was to observe the presence and impact of infection in adults of two toad species collected for captive breeding. The total number of animals included in the study was 162, but only subsets were used for sampling at different occasions (35 specimens in the initial sampling in summer 2011, 48 post hibernation during winter 2011, and 31 in summer 2012, after all toads in captivity were treated with itraconazole). We performed TaqMan real-time quantification PCR to detect and quantify the pathogen. We found that a large infection load was linked to mortality in a single adult green toad (Bufo viridis). However, low infection loads observed in five $B$. viridis and five natterjack toads ( $B$. calamita) were lost over time, with no apparent adverse effect. Intraconazole treated animals were all clear of infection. As infection in these two toad species either led to mortality or recovery, it seems unlikely they could act as permanent carriers of $B$. dendrobatidis and therefore persistence of the pathogen is likely maintained by different host species. This is the first study to date that has detected infection and observed its impact and persistence in wild-infected toads in Europe.
\end{abstract}

Batrachochytrium dendrobatidis, chytridiomycosis, Bufo, amphibian conservation

Batrachochytrium dendrobatidis is an important fungal pathogen of amphibians, which causes the cutaneous disease chytridiomycosis (Longcore et al. 1999). Whether infection persists and develops into disease is modulated by both external and intrinsic factors, including climatic conditions and host immunity (Fisher at al. 2007). The disease disrupts electrolyte transport through the skin and is often fatal (Voyles et al. 2009). The clinical signs include lethargy, dehydration, uneven skin shedding, loss of appetite, occasionally ulceration or necrosis of digits and neurological defects (Duffus and Cunningham 2010). However, these symptoms are non-specific and infection needs to be proven in the laboratory (Duffus and Cunningham 2010). The question of the geographic origin of the pathogen remains unanswered, but the fungus has already reached global distribution and infects over 350 amphibian species (Fisher et al. 2009). It is believed to be one of the causes of the current amphibian diversity crisis (Skerratt et al. 2007). As the extinction risk is different between various taxa of amphibians (Bielby et al. 2008), it is important to discriminate between the immune-, carrier- and susceptible-species in each region. Laboratory experiments and observations on species susceptibility are vital for understanding the outcome of infection in different taxa (Searle et al. 2011), and also enable data to be gathered which would often be unavailable in a field environment.

Presence of $B$. dendrobatidis in the Czech Republic was detected in 2008 (Civiš et al. 2012) with the documented host species including water frogs of the genus

Address for correspondence:

Vojtech Baláž

Department of Biology and Diseases of Wildlife

Faculty of Veterinary Hygiene and Ecology

University of Veterinary and Pharmaceutical Sciences Brno

Palackého tř. 1/3, Brno, 612 42, Czech Republic 
Pelophylax, the European fire-bellied toad (Bombina bombina), the yellow-bellied toad (Bombina variegata) and the common toad (Bufo bufo). All European species of the genus Bufo (taxonomy following Speybroeck et al. 2010) are known to be susceptible to infection (Garner et al. 2005; Ohst et al. 2011) and B. bufo has proven to be a great model in experimental studies (Garner et al. 2011). However, mortalities linked to $B$. dendrobatidis infection in toads of the genus Bufo from Europe are uncommon and limited to specific conditions (e.g. Bosch and Martinez-Solano 2006). All three European Bufo species (common toad Bufo bufo, natterjack toad B. calamita, green toad B. viridis) are present within the Czech Republic, and it is therefore an ideal area to study the interactions between $B$. dendrobatidis and the different species of this genus. Bufo bufo was shown to harbour the pathogen at low prevalence in the Czech Republic, however, there is no information available on $B$. dendrobatidis infection status and its impact to $B$. calamita and $B$. viridis, even though they are recognised as endangered species by national law and are included in numerous conservation and surveillance schemes.

The aim of this study was to monitor the pathogen in an ex-situ breeding project $B$. calamita and $B$. viridis to search for cases of acute chytridiomycosis and observe infection persistence in time.

\section{Materials and Methods}

In total, 162 adults of two toad species, B. calamita $(\mathrm{n}=113)$ and B. viridis $(\mathrm{n}=49)$ were collected from two localities in an area of open-pit mining in the western part of the Czech Republic (N50.212767 E12.605683 ${ }^{\circ}$ and $\mathrm{N} 50.245044^{\circ}, \mathrm{E} 12.671663^{\circ}$ ) post breeding in May 2011. Toads were captured as part of a project which focuses on amphibian captive breeding in artificial basins, by a company specialising in amphibian and reptile conservation (NaturaServis Ltd., Hradec Králové, www.naturaservis.net). The animals were housed in the basins throughout summer and autumn 2011. Up to 10 animals were accommodated in each of the 7 small basins ( $\operatorname{size} 8 \mathrm{~m}^{2}$ ) while 5 large basins ( per basin. The basins were filled with substrate from the sites of collection. Dry land covered $2 / 3$ of each basin and contained various hiding spots and plants. The remaining $1 / 3$ of the basin was a pool of water. The animals were fed crickets and sweep-netted insects twice a week.

Due to limited funding, only a subset of all animals could be sampled for $B$. dendrobatidis detection. Therefore two individuals were sampled per small basin and four individuals per large basin. One lethargic $B$. viridis male was housed separately and also sampled. This first sample set, collected in May 2011 thus contained 35 animals $(27 \mathrm{~B}$. calamita and 8 B. viridis).

All toads in captivity were put to hibernation in November 2011. They were sorted into groups of 4-5 individuals and placed in refrigerators at $4-5{ }^{\circ} \mathrm{C}$ in boxes with moistened substrate from the original locality. A subset of individuals from both species was kept at a lowered temperature of $1-2{ }^{\circ} \mathrm{C}$ (near-freeze treatment) for 10 days during December 2011

The second sampling phase took place in February 2012. The presence of infection by $B$. dendrobatidis was checked in all animals from the six basins where infection had been detected during initial sampling (48 specimens). Following the "near-freeze treatment", toads in this group were sampled individually $(n=24)$, but the samples were pooled for qPCR detection so DNA samples from all animals per hibernation box were used together as one sample. Although this could dilute the target DNA of the pathogen, it should not lower the chance of detection of positive individuals as was shown by Hyatt et al. (2007). Toads that were not near-freeze treated were also sampled individually $(n=24)$; if found positive, they were housed separately and resampled once a week until the end of hibernation (in total seven sampling occasions).

The toads were moved to breeding tanks in April 2012. In order to clear any potential B. dendrobatidis infection, all toads $(\mathrm{n}=162)$ were treated with Itraconazole post hibernation by daily bathing in a $0.01 \%$ itraconazole solution, for 11 successive days (as in Forzan et al. 2008). In order to stimulate any remaining infection, the water level in the tanks was increased for a period of 2 weeks in July (as advised by Trenton Garner, Zoological Society of London). Altogether 31 toads ( 24 B. calamita and 7 B. viridis) from basins that contained positive individuals after initial sampling in May 2011 were randomly selected for $B$. dendrobatidis detection, two weeks after this increased water treatment.

All samples in this study were collected by swabbing the skin using sterile rayon swabs MW100 (Medical Wire). Sampling and DNA extraction using PrepMan Ultra (Applied Biosystems, UK) followed the standard protocols (Boyle et al. 2004; Hyatt et al. 2007). Sample homogenisation was performed by MagNA Lyser (Roche Diagnostics, CZ). B. dendrobatidis detection was performed by real-time qPCR (Boyle et al. 2004), but with the addition of bovine serum albumin (BSA) to lower PCR inhibition (Garland et al. 2010), reduction of volume of the reaction and running the reactions in triplicates (Hyatt et al. 2007) 
using Light Cycler 460 II system with original Roche reagents. DNA quantification standards were provided by the Institute of Zoology, Zoological Society of London. The standards are made by isolation of the pathogen's DNA from exactly counted zoospores. Comparing the results of unknown samples to standard curve based on the standards allows quantification of the pathogen in the sample with the unit being GE = genomic equivalent of one zoospore (Boyle et al. 2004). The method represents the most commonly used option in studies that need high sensitivity and ability to distinguish the infection intensities among sampled amphibians.

\section{Results}

During the initial field sampling period in May $2011(\mathrm{n}=35)$, an infection prevalence of $18.5 \%$ was detected in B. calamita (5 out of $27 ; 95 \% \mathrm{CI}=7.6-36.9$ ) and $87.5 \%$ in $B$. viridis $(6 / 8 ; 95 \%$ CI 50-99.4). Infection intensity ranged from $0.3-58 \mathrm{GE}$ in $B$. calamita and $1.3-13,750 \mathrm{GE}$ in $B$. viridis. The individual $B$. viridis with the highest score was in poor physical condition at the time of swab collection. This animal was quarantined, but died the following day with no further tests/analysis carried out on its carcass.

The second sampling period, carried out in February 2012 during hibernation $(n=48)$ gave one positive result from $B$. calamita with a GE of 1.9 (SD 0.4). All other animals tested were negative during that time. The positive animal was not included in the initial sampling period, and was not among those that received the near-freeze treatment. Infection load in the positive animal decreased during the period of hibernation from 1.9 GE to $0.63 \mathrm{GE}$ on $28^{\text {th }}$ February and $0.40 \mathrm{GE}$ on $6^{\text {th }}$ March. The following sampling of this animal that was done once per week (from 13 March until 4 May) gave a negative result.

All animals survived hibernation in good condition. No animals tested were found positive during the third sampling occasion $(n=31)$ in July 2012 , following the water increase treatment.

\section{Discussion}

Keeping wild collected animals in captivity allows observation of processes that would otherwise go undetected. It is reasonable to expect that mortality of infected individuals occurs in times of climatic stress or during hibernation, when the animals are hidden. Mortality in such conditions is especially difficult to study in a field environment and it is possible that important population regulating factors go undetected. Naturally infected animals carry a local strain of the pathogen and naturally occurring infection dose, therefore their observation brings better insight of the infection result in realistic conditions.

High infection load found on one specimen of $B$. viridis was linked with lethargy and later, mortality. Although no histological examination was performed, it can be presumed this mortality was a results of fatal chytridiomycosis, as such high levels of infection $(>10,000 \mathrm{GE})$ are often regarded as a sign of acute chytridiomycosis (Vredenburg et al. 2010; Kinney et al. 2011). Our findings also imply that intense infections can be linked to mortality in adult B. viridis and similarly in B. calamita (Bosch and Martinez-Solano 2006), both species are able to clear mild infection or suppress it to levels undetectable by qPCR. As our sampling effort had apparent limitations in sample size and timing of sampling, our data did not show exactly when the loss of infection occurred and we were not able to track the individual changes of infection over time. However, our data still bring interesting results. The single individual that was found positive during hibernation lost any detectable infection before the end of overwintering, surprisingly at a time when the amphibian immune system is suppressed by temperature (Ribas et al. 2009). It is possible that relatively low humidity of the skin and temperature below optimal caused stress to 
the fungus and lead to a loss of infection or reduction of its quantity in the outer skin layer below a detectable level. Our results highlight a very intriguing question as to where the fungus overwinters and which species contribute to its survival during winter. Dormant stages of the fungus could allow survival of harsh conditions independently from the host but to our knowledge, this life stage has not been described in $B$. dendrobatidis so far. Based on our findings, toads seem unlikely to be permanent reservoirs of $B$. dendrobatidis. If overwintering and long term survival of this fungal pathogen is maintained by a limited number of species, it may help to direct future mitigation attempts, at least in countries with temperate climate.

\section{Acknowledgements}

We thank Frances Clare (ZSL London) who provided valuable comments and greatly improved the English, and Trenton Garner (ZSL London) for advice and help during the course of the study. This study was supported by the Research Project of the Technology Agency of the Czech Republic No. TA01020881. Permission to keep the protected species was issued by The Hradec Králové Regional Authority (23879/ZP/2010-Br-6 and 2353/ ZP/2010-Br-6).

\section{References}

Bielby J, Cooper N, Cunningham AA, Garner TWJ, Purvis A 2008: Predicting susceptibility to future declines in the world's frogs. Cons Lett 1: 82-90

Bosch J, Martinez-Solano I 2006: Chytrid fungus infection related to unusual mortalities of Salamandra salamandra and Bufo bufo in the Penalara Natural Park, Spain. Oryx 40: 84-89

Boyle DG, Boyle DB, Olsen V, Morgan JAT, Hyatt AD 2004: Rapid quantitative detection of chytridiomycosis (Batrachochytrium dendrobatidis) in amphibian samples using real-time Taqman PCR assay. Dis Aquat Organ 60: $141-148$

Civiš P, Vojar J, Literák I, Baláž V 2012: Current state of Batrachochytrium dendrobatidis occurence in the Czech Republic. Herpetol Rev 43: 150-159

Duffus AJL, Cunningham AA 2010: Major disease threats to European amphibians. Herpetol J 20: 117-127

Fisher MC 2007: Potential interactions between amphibian immunity, infectious disease and climate change. Anim Conserv 10: 420-421

Fisher MC, Garner TWJ, Walker SF 2009: Global Emergence of Batrachochytrium dendrobatidis and amphibian chytridiomycosis in space, time, and host. Annu Rev Microbiol 63: 291-310

Forzan MJ, Gunn H, Scott P 2008: Chytridiomycosis in an aquarium collection of frogs: Diagnosis, treatment, and control. J Zoo Wildlife Med 39: 406-411

Garland S, Baker A, Phillott AD, Skerratt LF 2010: BSA reduces inhibition in a TaqMan (R) assay for the detection of Batrachochytrium dendrobatidis. Dis Aquat Organ 92:113-116

Garner TWJ, Rowcliffe JM, Fisher MC 2011: Climate change, chytridiomycosis or condition: an experimental test of amphibian survival. Glob Change Biol 17: 667-675

Garner TWJ, Walker S, Bosch J, Hyatt AD, Cunningham AA, Fisher MC 2005: Chytrid fungus in Europe. Emerg Infect Dis 11: 1639-1641

Hyatt AD, Boyle DG, Olsen V, Boyle DB, Berger L, Obendorf D, Dalton A, Kriger K, Hero M, Hines H, Phillott R, Campbell R, Marantelli G, Gleason F, Colling A 2007: Diagnostic assays and sampling protocols for the detection of Batrachochytrium dendrobatidis. Dis Aquat Organ 73: 175-192

Kinney VC, Heemeyer JL, Pessier AP, Lannoo MJ. 2011: Seasonal pattern of Batrachochytrium dendrobatidis infection and mortality in Lithobates areolatus: Affirmation of Vredenburg's "10,000 zoospore Rule". PLoS ONE 6: e16708

Longcore JE, Pessier AP, Nichols DK. 1999: Batrachochytrium dendrobatidis gen. et sp. nov., a chytrid pathogenic to amphibians. Mycologia 91: 219-227

Ohst T, Gräser Y, Mutschmann F, Plötner J 2011: New data about the threat of chytridiomycosis to European amphibians (In German). Zeitschrift für Feldherpetologie 18: 1-17

Ribas L, Li MS, Doddington BJ, Robert J, Seidel JA, Kroll JS, Zimmerman LB, Grassly NC, Garner TWJ, Fisher MC 2009: Expression profiling the temperature-dependent amphibian response to infection by Batrachochytrium dendrobatidis. PLoS ONE 4: 1-10

Searle CL, Gervasi SS, Hua J, Hammond JI, Relyea RA, Olson DH, Blaustein AR 2011: Differential host susceptibility to Batrachochytrium dendrobatidis, an emerging amphibian pathogen. Cons Biol 25: 965-974

Skerratt LF, Berger L, Speare R, Cashins S, McDonald KR, Phillott AD, Hines HB, Kenyon N 2007: Spread of chytridiomycosis has caused the rapid global decline and extinction of frogs. EcoHealth 4: 125-134

Speybroeck J, Beukema W, Crochet P-A 2010: A tentative species list of the European herpetofauna (Amphibia and Reptilia) - an update. Zootaxa 2: 1-27 
Voyles J, Young S, Berger L, Campbell C, Voyles WF, Dinudom A, Cook D, Webb R, Alford RA, Skerratt LF and Speare R. 2009: Pathogenesis of chytridiomycosis, a cause of catastrophic amphibian declines. Science 326: $582-585$

Vredenburg VT, Knapp RA, Tunstall TS, Briggs CJ 2010: Dynamics of an emerging disease drive large-scale amphibian population extinctions. P Natl Acad Sci USA 107: 9689-9694 